\title{
sciendo
}

10.2478/aucft-2020-0022

\section{MATHEMATICAL MODELLING AND NUMERICAL SIMULATION OF MASS TRANSFER DURING DEEP-FAT FRYING OF PLANTAIN (MUSA PARADISIACAL AAB) CHIPS (IPEKERE)}

- Research paper -

\author{
James Abiodun ADEYANJU ${ }^{1 *}$, John Oluranti OLAJIDE* ${ }^{*}$ Emmanuel Olusola OKE**, Akinbode \\ Adeyemi ADEDEJI***
}

\author{
*Department of Food Engineering, Ladoke Akintola University of Technology, Ogbomoso, Oyo \\ State, Nigeria \\ ** Department of Chemical Engineering, Michael Okpara University of Agriculture, Umudike-Abia \\ State, Nigeria \\ ${ }^{* * *}$ Department of Biosystems and Agricultural Engineering, University of Kentucky, Lexington, KY, \\ USA
}

\begin{abstract}
This study developed a mathematical model following the fundamental principles of mass transfer for the simulation of the oil and moisture content change during the Deep-Fat Frying of plantain (ipekere) chip. The explicit Finite Difference Technique (FDT) was used to conduct a numerical solution to the consequential governing equation (partial differential equation) that was used to describe the mass transfer rate during the process. Computer codes that were computed in MATLAB were used for the implementation of FDT at diverse frying conditions. Samples of the plantain were cut into portions of $2 \mathrm{~mm}$ thickness, and these sliced portions were fried at separate frying oil temperatures $\left(170,180\right.$ and $\left.190^{\circ} \mathrm{C}\right)$ between 0.5 and 4 minutes. The experimental data and the predicted outcomes were compared for the validation of the model, and the juxtaposition revealed a plausible agreement. The predicted values and the experimental values of oil and moisture transfer models produced correlation coefficients that range from 0.96 to 0.99 and 0.94 to 0.99 , respectively. The predicted outcomes could be utilized for the control and design of the DFF.
\end{abstract}

Keywords: mass transfer, moisture loss, oil uptake, frying, plantain

\section{INTRODUCTION}

Plantain (Musa paradisiacal AAB) belongs to the Musaceae family, and it is planted in a lot of subtropical and tropical countries around the globe. The two dominant nations in Africa that produce substantial quantity, consume as staple, and exports plantain are Nigeria and Cameroon. These two countries are categorized among the top twenty plantain producing countries globally (FAO, 2013). Plantain is majorly a source of carbohydrate, and the caloric needs of people in a number of the developing countries are satisfied by plantains. It can be eaten raw when ripe, which makes it a major source of vitamin $\mathrm{C}$ and other essential minerals. However, as claimed by Demirel and Turhan (2003), they are highly perishable and susceptible to fast deterioration as a result of increased metabolic activity and excessive

Received: 26.05.2020.

Accepted in revised form: 15.08 .2020 moisture content, which continues after harvesting. Traditionally, many value-addition processes have been applied to plantain to form many food products like fully ripe fried plantain (dodo), boiled plantain, roasted plantain (boli), plantain flour (elubo), plantain chips (ipekere), alcoholic beverages and others. These conversion processes reduce the deterioration rate while they also add value to the product.

Generally, deep-fat frying of food is considered as one of the most prevalent units of operation that is utilized during the process of food preparation. Hence, an understanding of the frying mechanism is necessary for the production, preservation and marketing of fried food optimally. It could be regarded as high temperature and short time process, which entails both mass transfers (mostly illustrated by oil uptake and water loss), and heat transfer (Vitrac et al., 2002). Sealing the food with a crispy crust made from the immersion of the food in hot oil for the retainment of all the juice and flavours is one of the primary purposes of DFF

${ }^{1}$ Corresponding author. E-Mail address: jaadeyanju@lautech.edu.ng 
(Garcia et al., 2002). It leads to products with a different flavour-texture combination (Mellema, 2003; Pedreschi, 2012).

There is an increasing emphasis all over the world for the consumption of food products that will not constitute health hazards to consumers (Bouchin et al., 2003; Adedeji et al., 2009; Adedeji and Ngadi, 2011; Adeyanju et al., 2016). Among highly patronized food industries is the snack food industry, where concerted efforts are being made in reducing the amount of oil content in the snack class of DFF. This is important because the consumption of high fatty foods is a precursor to obesity, diabetes and heart-related diseases, hence, high caloric nutrition is now a major health challenge for everyone (Krokida et al., 2001). The major problem is the manner of improving the frying process through a reduction of the final oil content of the fried products in the absence of a deterioration of their desirable organoleptic properties. Achieving this goal may be dependent on optimizing the frying process conditions, consideration of the nature of the material being fried and the medium of frying. The interrelationships of these variables are complex but crucial to the quality of the final products. A good knowledge of the mass transfer phenomena, especially oil uptake and moisture loss, and how they relate to processing conditions namely; frying temperature and duration would help in designing an optimal process for DFF of plantain. This is possible through virtual simulations of the processing conditions and developing mathematical models that can be used to predict behaviour under a different scenario.
A mathematical model describes the timedependent practice of the process; this model or pattern is appropriate for simulation of transient behaviour, an examination of start-up, shutdown conditions and control strategies of the frying process. The design of equipment for the process is developed and enhanced by the modelling of the process, which also provided better understanding into the operation of frying of plantains, which results into optimal process and the control of the operation. Many researchers have used the finite difference technique to develop a pattern for the prediction of oil and moisture transfer during DFF of foods. Ateba and Mittal (1994) worked on modelling the DFF of beef meatballs using finitedifference. Ngadi et al. (1997) used a finite element method pattern to generate a pattern for moisture transfer in the chicken drum during the process of deep-fat frying of food. Chen and Moreira (1997) conducted research on tortilla chips, and they studied the modelling of a batch deep-fat frying process. The effects of diverse frying conditions on moisture, temperature and oil profiles during the process of frying tortilla chips were analysed using a mathematical computation. However, little or no attention has been paid to the mathematical computation of mass transfer during the process of frying plantain into different products. The study is therefore focused on the development of a mathematical model that predicts oil uptake and moisture loss in DFF of ipekere towards ensuring that the nutritional values of the food product is preserved while extending its shelflife.

\section{MATERIALS AND METHODS}

\section{Sample collection and preparation}

Mature green and freshly harvested plantain utilized in this research was gotten from a farm in Ogbomoso, Nigeria. In a similar way to Aurore et al. (2009) method, the fruits were utilized at stage 1 of ripeness by using colour index chart. It was transported to the Food Processing Laboratory at Ladoke Akintola University of Technology, Ogbomoso, Nigeria for the experiment. A knife (stainless steel) and a vegetable slicer (Model ART No: SF-923-1, Texas USA) were used to peel the fruits and cut them into a disc size of $2 \mathrm{~mm}$ thickness. Refined palm olein oil (Ngo Chew Hong Ltd, Singapore) was used for frying in a deep-fat fryer (model S-576, M/S Assudamal \& Asons (HK) Ltd., Hong Kong, China) that was adapted with a PID temperature controller for the maintenance of the set frying temperature within $\pm 1^{\circ} \mathrm{C}$. The fryer equipped with a $2 \mathrm{~kW}$ electric heater was filled with $3 \mathrm{~L}$ of oil. Plantain slices to oil ratio were kept at $1: 25$ by volume. At temperatures 170,180 and $190^{\circ} \mathrm{C}$, the plantains were fried between 0.5 and 4 minutes. The plantain samples were taken away from the fryer and put on a stainless steel grid for $10 \mathrm{~min}$ after frying to allow the excess oil to be removed from the fried products. Sealed and low-density polyethylene bags were used to store the samples, and they were stored at room temperature until other analyses were being conducted within six hours of frying.

\section{Determination of the oil and moisture content}

AOAC (2000) method was used to determine the oil and moisture contents. The process of drying the fried samples in an oven (Gallemkamp Scientific, UK) at a temperature $105^{\circ} \mathrm{C}$ until 
constant volume was used for the determination of the moisture content. A balance was utilized in the measurement of the mass of the product before and after drying. Percentage differences between the initial and final weight of the plantain samples were determined, and the differences were recorded as the percentage moisture content. With petroleum ether, oil content determination was conducted using Soxhlet Extractor (SER 148, VelpScientifica, Usmate, Italy). For solvent extraction, an approximate $3 \mathrm{~g}$ of the samples were weighed into thimbles. Under vacuum at $60^{\circ} \mathrm{C}$, the petroleum ether was extracted through a rotary evaporator. The differences in the percentage of the sample were named as the oil content. All analyses conducted in this study were performed in three separate folds.

\section{Mathematical model formulation}

\section{Plantain chips frying problem description}

Moisture migrates (diffuses) out from the plantain chip in the form of vapour during frying, and some of the frying oil also simultaneously enters the chip as well. Therefore, diffusion of moisture and frying oil are in two opposing ways. As the moisture content in the sample reduces, the oil content increases in the sample; this causes the chip to become more porous during frying. Two areas, that is, crust and core, exist during frying; the crustcore boundary moves towards the center of the chip during the process of frying. At the boundary or the interface, to allow the water present in that boundary to evaporate, the temperature remains at the water boiling point for a short period.

\section{Model assumptions}

Therefore, in the model or pattern development, the following assumptions were considered:
(1) The temperature distributions and initial moisture content in the chip are uniform.

(2) The thickness of the chip is reduced in comparison with the other dimensions, infinite slab geometry was presumed in the study and onedimensional mass transfer model was considered.

(3) The heat required for chemical reactions (i.e. starch gelatinization and protein denaturation is less in comparison with the heat needed in the evaporation of water.

(4) During the frying process, the functions of moisture content and local temperature were physical and thermal properties.

\section{Development of governing equations}

The mathematical model for moisture transfer rate during frying was developed using a slab of plantain chip, from the first principle approach: frying oil diffuses into the sample, and moisture is transferred out of the material. Conservation of mass in a differential element of the chip was accomplished by defining appropriate initial and boundary conditions. Species conservation in a differential volume, that is, deepfat frying process control, is presented in Figure 1.

Rate of mass transfer = Influx of mass into the tissue - Out flux of mass from the tissue

The time rate of change of water in the tissue: = $\frac{\partial(c) A x}{\partial t}$

Influx of water into the tissue $=j$

Out flux of water from the tissue $=j+\frac{\partial_{j}}{\partial_{x}}$

Substitute equation $1,2,3$ into the statement of species conservation and it gives:

$$
\begin{aligned}
& \frac{\partial(c) A x}{\partial t}=j-\left(j+\frac{\partial_{j}}{\partial_{x}} A x\right) \\
& \frac{\partial(c) A x}{\partial t}=-\left(+\frac{\partial_{j}}{\partial_{x}} A x\right)
\end{aligned}
$$

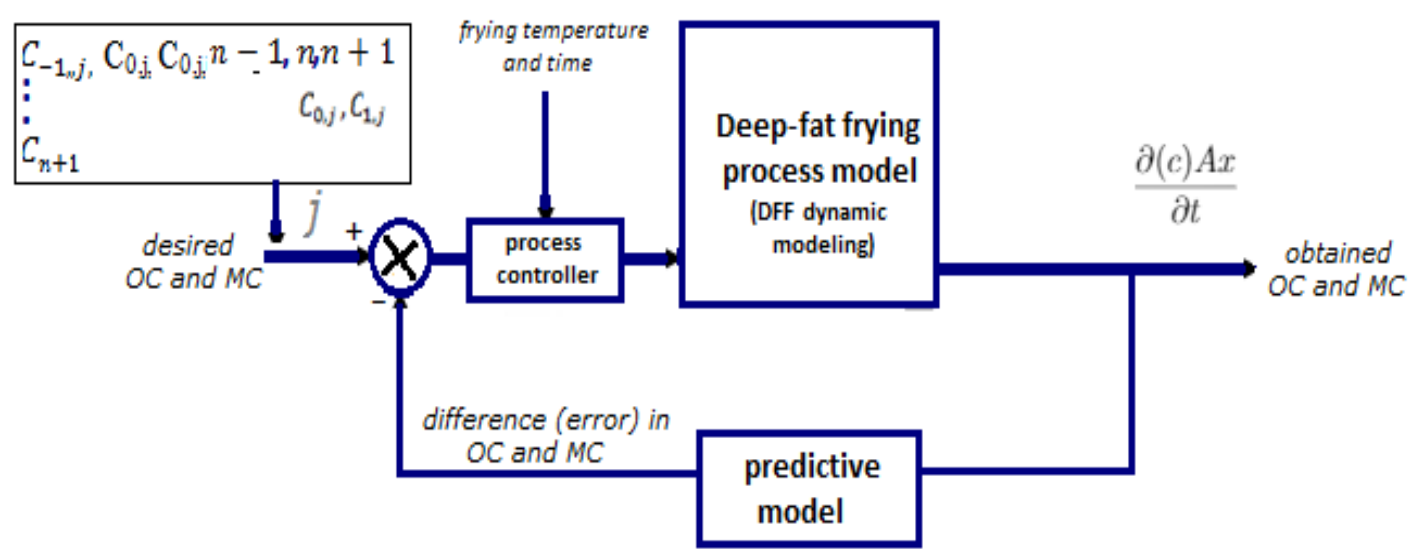

Figure 1. Species conservation in a differential volume (elemental tissue of the plantain), that is, DFF process control 
Divide equation (5) by $A x$ and it becomes:

$\frac{\partial c}{\partial t}=-\frac{\partial j}{\partial x}$

Recall, Fick's first law of diffusion:

$j=-D_{\text {eff }} \frac{\partial c}{\partial x}$

$D_{\text {eff }}=$ Effective diffusion coefficient

$\mathrm{C}=$ concentration of species (moisture or oil) in a mixture, $\mathrm{mol}$ (or mass) $/ \mathrm{m}^{3}$.

$x=$ plantain thickness $(\mathrm{m})$

$j=$ flux of the mass relative to the chip (number of species crossing unit plane per unit time)

Now, combine equation 6 and 7 and obtain:

$\frac{\partial c}{\partial t}=\frac{\partial c}{\partial t} D \frac{\partial c}{\partial t}$

Equation 8 is an appropriate equation for the prediction of mass transfer rate during plantain chip frying.

The initial and boundary conditions that were used are as follows:

\section{Initial condition:}

$C(t=0, x)=C_{0}$

\section{Boundary conditions}

$C(t=0, x)=C_{e}$

$C(x=L, t)=C_{e}$

Numerical solution of the mathematical model

The explicit finite difference method of solution was used in solving the equation, then the equation was changed into an entirely distinct equation through a division of the domain of solution to a grid of points in the form of mesh and the derivatives are represented along each mesh point known as a node. At each node, the dependent variable was initially known and approximated for the next time step until the final step of the domain. The numerical grid of the solution domain is shown in Figure 2. It entails two perpendicular lines, which represent the $x$-direction and $t$ direction. Hence, the finite difference representation of the mesh points is as follows:

$X i=i \delta x$ for $i=0,1,2 \ldots \ldots \ldots m$

$Y i=j \delta t$ for $i=0,1,2 \ldots \ldots \ldots n$

where $\delta x$ and $\delta t$ represent the sizes of the grid in the $x$ and $t$ directions, respectively, and subscripts signify the area of the dependent variable under scrutiny.

The finite difference representations of various derivatives that show in the governing equation are gotten from Taylor's series expansion. Through the application of Taylor's series expansion in $t$ (time) direction but by keeping $x$ (space) constant and truncating the second term of the series for the left hand of the governing equation, therefore, Finite Difference Equation (FDE) of LHS of equation (8) was obtained:

$\frac{\partial c}{\partial t}=\frac{C_{i . j+1}-C_{i, j}}{\delta t}$

Similarly, by applying, Taylor's series expansion in the (space) direction, keeping $t$ constant; and again, Taylor's series expansion in the $x$-direction (backward difference), keeping $t$ constant. Therefore, FDE of RHS of equation (8) was obtained:

$\frac{\partial^{2} c}{\partial^{2} x}=\frac{C_{i .-1}-2 C_{i, j+} C_{i+1, j}}{(\delta x)^{2}}$

Equate (14) and (15) to represent the governing equation:

$\frac{C_{i . j+1}-C_{i, j}}{\delta t}=\frac{C_{i .-1}-2 C_{i, j+} C_{i+1, j}}{(\delta x)^{2}}$

$C_{i . j+1}-C_{i, j}=\frac{\delta t}{(\delta x)^{2}} C_{i .-1}-2 C_{i, j+} C_{i+1, j}$

$C_{i . j+1}=C_{i, j}+r\left[C_{i .-1}-2 C_{i, j+} C_{i+1, j}\right]$

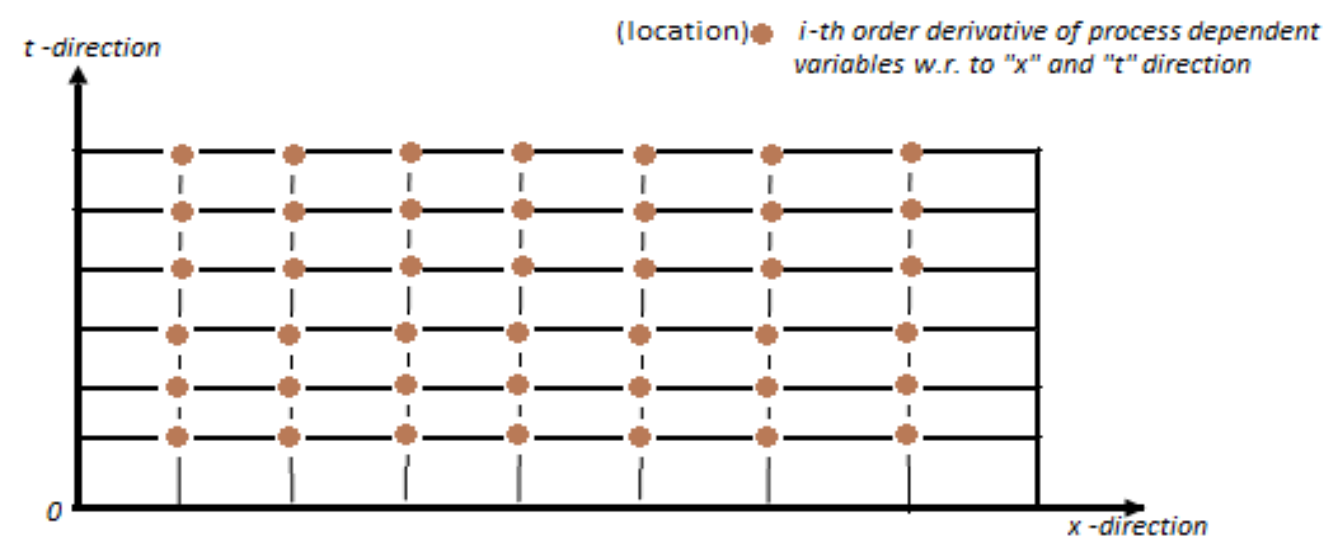

Figure 2. Numerical grid illustration for a slab of plantain chip during DFF process using FDE 
At $x=0$, then, $i=0, C_{0 . j+1}=C_{0, j}+$

$r\left[C_{-1, j}-2 C_{0, j}+C_{+1, j}\right]$

Then, $C_{-1, j}$ (pseudo concentration at the external mesh point is assumed in equation (18) is calculated.

To represent $\frac{\partial C}{\partial x}$ more accurately at $x=0$ by the central difference formula, it is necessary to introduce the pseudo concentration $C_{-1, j}$ at the external mesh point by imagining the sheet of the tissue is extended very slightly. Therefore, finite difference approximation at boundary $x=0$ in terms of central difference representation:

$\frac{C_{1, j-} C_{-1, j}}{2 \delta x}=C_{0, j}$

From equation 19, external mesh point becomes:

$C_{-1, j}=C_{1, j}-2 \delta x C_{0, j}$

Through substitution of equation 20 into equation 18, you will get:

$C_{0 . j+1}=C_{0, j}+2 r\left[C_{1, j}-C_{0, j}(1+\delta x)\right]$

Equation (21) is the discretized equation of mass transfer equation for every node, and this algebraic relationship was used to derive the transient oil and moisture content at each node. The value of parameters used in the simulation of plantain chips is presented in Table 1 .

Table 1. Experimentally determined parameters used in the simulation of fried plantain chips

\begin{tabular}{ll}
\hline Parameter & Value \\
\hline Initial moisture content & $65.13 \%$ \\
Initial fat content & $14.59 \%$ \\
Thickness & $2 \mathrm{~mm}$ \\
Effective Moisture diffusivity & $7.24 \times 10^{-6} \mathrm{~m}^{2} / \mathrm{s}$ \\
Effective Fat diffusivity & $1.27 \times 10^{-6} \mathrm{~m}^{2} / \mathrm{s}$ \\
\hline
\end{tabular}

\section{RESULTS AND DISCUSSION}

\section{Moisture loss - experimental and predicted}

Figure 3 compares experimental and predicted moisture transfer rate at varying temperatures $\left(170-190^{\circ} \mathrm{C}\right)$ and frying time $(0.5-4$ minutes $)$. It was observed that the proportion of moisture content reduction at 30 second is between $45-54$ $\mathrm{kg} / \mathrm{kg}$.db as presented in Figure 3. The highest moisture content removal from the chip was obtained between 1.5 - 2 minutes as revealed in Figure 3. However, little moisture content removal was achieved from 90 - 240 seconds at all frying conditions (Figure 3). It was also observed from the graphs that about $87-90 \%$ of moisture were removed in the frying process. Therefore, the rate of frying was fast in the first 60 - 100 seconds of the process, the rate of frying becomes slow as the product reaches equilibrium; this is very similar to

\section{Grid sensitivity, stability, and simulation}

The mathematical development of moisture/oil transfer during plantain chip frying at the level of discretization of the governing equation is still crude. It may not represent the exact solution of the governing equation; thus, this needs necessary refining via grid sensitivity, stability, and convergence.

Therefore, in order to explore the effect of $\Delta t$ and $\Delta x$, a sensitivity analysis was performed. Then, the value of time and space was determined using stability criteria. The criterion $\left(r=\frac{D_{\delta t}}{\delta x} \leq\right.$ $\left.\frac{1}{2}, \frac{D_{\delta t}}{\delta y} \leq \frac{1}{2}\right)$ for stability and convergence of the solution was satisfied during the simulation process in the MATLAB environment. Where $\mathrm{D}=$ effective diffusivity, $x=$ the thickness of the sample and time is frying time. The above criterion was the maximum permeable value used for computer simulation of the process. A series of computer simulations were done for the discretized pattern or model to investigate the effect of time and distance grid size on the output (oil/moisture content) of Matlab computer codes. Then, the correlation coefficient for simulated results with experimental data was performed, in the MATLAB environment, for the determination of the degree of model predictability. Using the Mean Relative Deviation Modulus (MRDM) (\%E), the agreement between predicted and experimental results was further evaluated as indicated in Equation 22:

$\% E=\frac{1}{n} \sum \frac{\left|V_{E}-V_{P}\right|}{V_{E}}$

where: $V_{E}=$ Experimental value, $V_{P}=$ Predicted value. a previous study by Adedeji et al. (2009). The result obtained is similar to the findings in the literature by Krokida et al. (2001); Bravo et al. (2009); Adedeji et al. (2009; Manjunatha et al. (2012).

Mean Relative Deviation Modulus (MRDM, \%E) was used to measure moisture removal prediction accuracy. MRDM for $170,180,190^{\circ} \mathrm{C}$ frying temperatures are $2.31 \%, 2.15 \%$ and $2.621 \%$, respectively. The MRDM values are generally low. Azoubel and Murr (2002) reported that the value of MRDM less than or equal to $10 \%$ predicts accurately the experimental data, and the model for the predictive purpose is better determined by a lower percentage. This indicates that the model for moisture removal during frying of plantain chips made satisfactory predictions. A comparison of the correlation coefficients was done between predicted and experimental values; this gave high 
correlation coefficients, which ranges from 0.955 to 0.997 .

\section{Oil uptake}

Figure 4 shows curves of predicted and experimental oil uptake during frying of ipekere between process time ( 0.5 - 4 minutes) and varying temperatures $\left(170,180\right.$ and $\left.190^{\circ} \mathrm{C}\right)$. The curves in Figure 4 show that as the process time increases the rate of oil impregnation into the chip increases and this i similar to earlier works described in the literature (Krokida et al., 2001; Ziaiifar et al., 2008; Manjunatha et al., 2012; Adedeji and Ngadi, 2018). It was observed that highest oil absorption into the chip was achieved at the beginning of frying process as shown in Figure 4. The predicted results for oil uptake during the frying process provide a satisfactory prediction of experimental data, as indicated in Figure 4, with MRDM less than $10 \%$. MRDM for $170,180,190{ }^{\circ} \mathrm{C}$ are $3.41 \%$, $3.5 \%$ and $3.521 \%$, respectively. It could be seen that the prediction showed a good correlation with experimental data with the value of MRDM obtained between experimental and predicted results. The obtained values for the correlation coefficient for the predicted and experimental data ranged from 0.939 to 0.996 .

\section{Simulation of moisture and fat content profiles at different diffusivities}

Plantain chips frying moisture diffusivity value of $1.41 \times 10^{-6} \mathrm{~m}^{2} / \mathrm{s}$ (obtained experimentally at $190^{\circ} \mathrm{C}$ ) was used for moisture content profile simulation in this study.

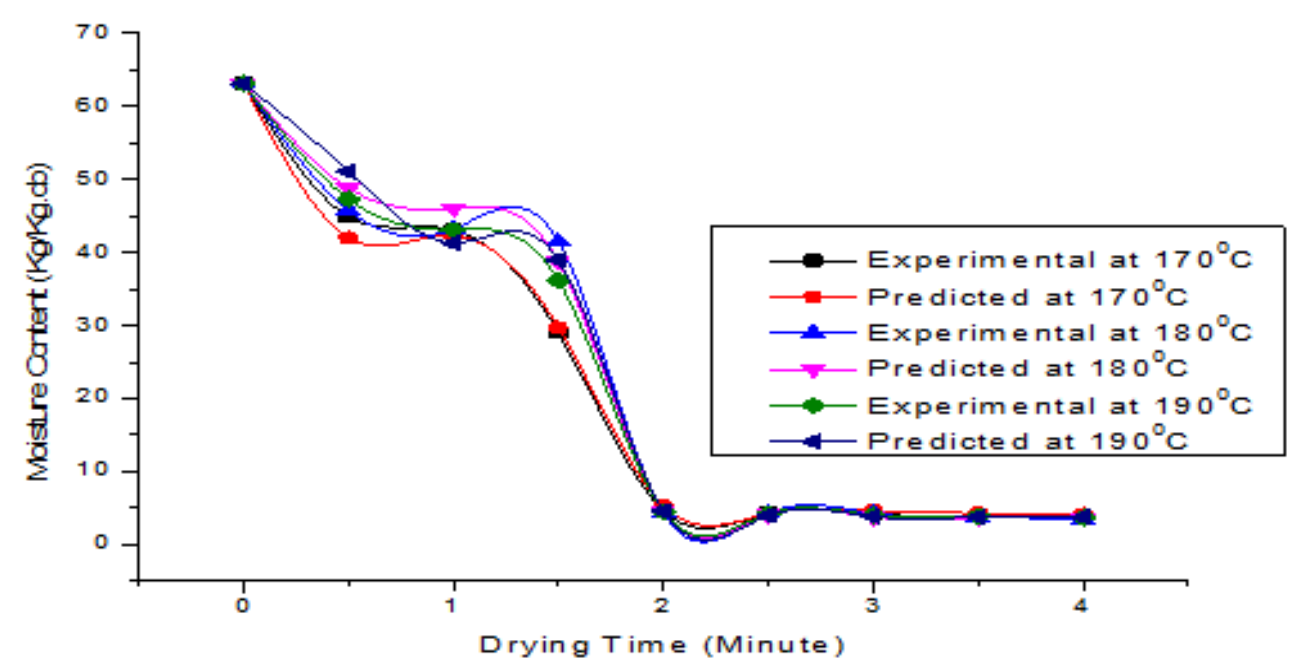

Figure 3. Comparison of experimental and predicted moisture profiles at 170,180 and $190{ }^{\circ} \mathrm{C}$

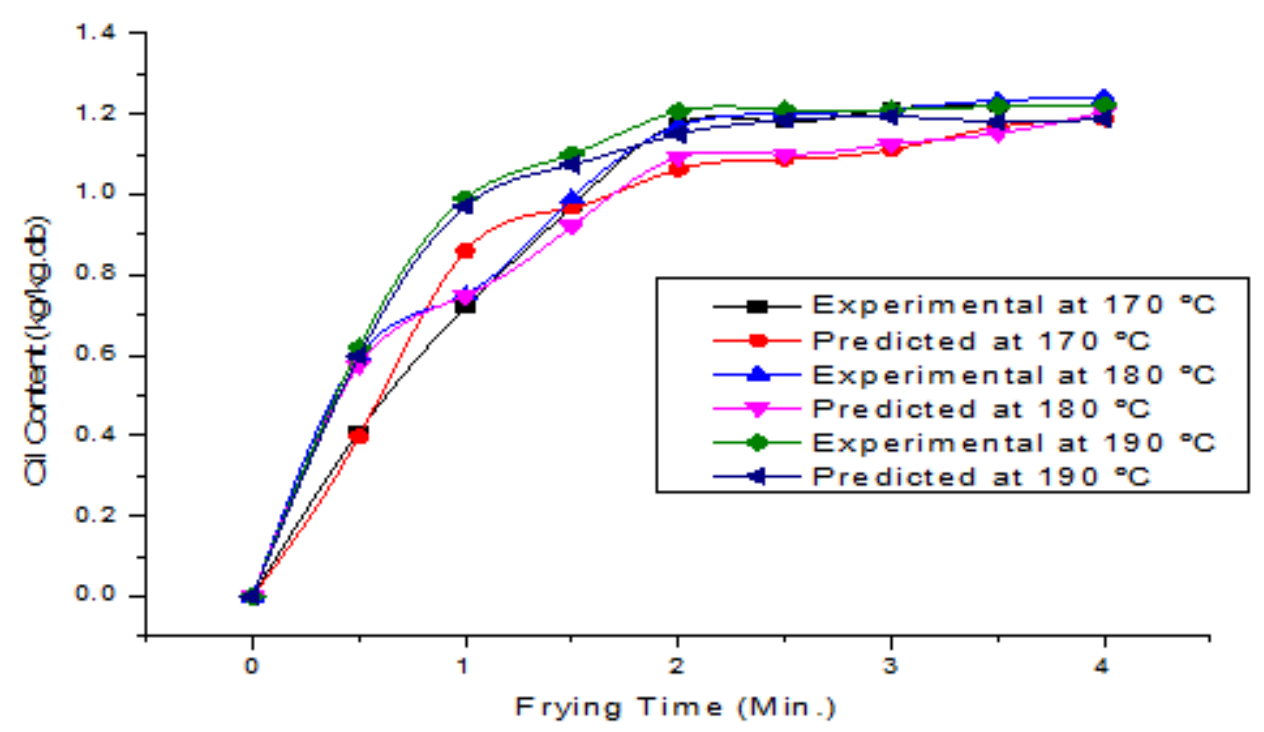

Figure 4. Comparison of experimental and predicted fat content profiles at 170,180 and $190^{\circ} \mathrm{C}$ 
The value of the diffusivity in MATLAB computer program was changed by increasing the diffusivity value of $1.4 \times 10^{-6} \mathrm{~m}^{2} / \mathrm{s}$ twenty-five (25) percent and fifty (50) percent (i.e. $1.7 \mathrm{x} 10-6 \mathrm{~m}^{2} / \mathrm{s}$ and $2.1 \mathrm{x}$ $10-6 \mathrm{~m}^{2} / \mathrm{s}$ respectively) in order to simulate moisture content profile at different mass transport conditions; and evaluate the effect of diffusivity on the plantain chip frying. Figure 5 shows frying moisture content profiles at different diffusion coefficients. It was observed that the rate of moisture transfer from plantain chip during the process is diffusivity-dependent; because the highest diffusivity poses highest moisture loss during the process as indicated in Figure 5. The trend of the findings obtained from this study is similar and consistent to that of Zhan et al. (2015). It is therefore concluded that the frying process is sensitive to changes in the diffusion coefficient of the process. Besides, the findings obtained from this study shows that the diffusivity of the frying process is of great important to food process engineer during frying process design, optimization and control. Moreover, the simulation results show that the moisture content profile of plantain frying process could be obtained, once the diffusivity of the process is known, using numerical simulation approach instead of frying experimentation study which is time-consuming and cost expensive. For fat profile content, the value of the diffusivity in MATLAB computer program was also altered by increasing the diffusivity value of $1.2 \times 10-6 \mathrm{~m}^{2} / \mathrm{s}$ by $25 \%$ and $50 \%$ to simulate fat content profile at different mass transport conditions. Figure 6 shows frying fat content profiles at different diffusion coefficients. It was observed that the highest diffusion coefficient value has the highest transfer of mass during the process. The graph revealed that as the fat diffusivity property value increases, the rate of fat migration from the plantain increases as shown in Figure 6.

\section{Prediction of moisture and fat content distribution at different locations}

Figure 7 presents the simulated moisture distribution profile of plantain chips at different axial locations during the frying process at $190^{\circ} \mathrm{C}$ frying temperature. It is observed that the frying rate is proportional to the axial distance from the centre of chip sample, where the distance of $0.0002 \mathrm{~mm}$ from the centre of the sample has the highest moisture removal rate as shown in Figure 7.

The highest moisture content removal rate observed at the chip surface relative to inner surfaces could be explained in terms of the bulk mass transfer resulting from direct interaction with the frying liquid (Kassama and Ngadi, 2005; Zhan et al., 2015). It was also noted that the lowest moisture content removal was at $0.001 \mathrm{~mm}$ as indicated in Figure 7.

Figure 8 presents simulated fat distribution profile of plantain chips $(2 \mathrm{~mm})$ at different spatial locations in the process of frying at temperature $190^{\circ} \mathrm{C}$. The rate of fat impregnation was rapid at the surface of the sample $(0.001 \mathrm{~mm})$. However, the time of frying increases just as the rate of fat transfer into the sample decreases (Figure 8). It was also noticed that the inner locations possess the highest fat content as indicated in Figure 8. This suggests that the moisture transfer model could be used to predict the moisture removal rate at different spatial positions and frying temperature.

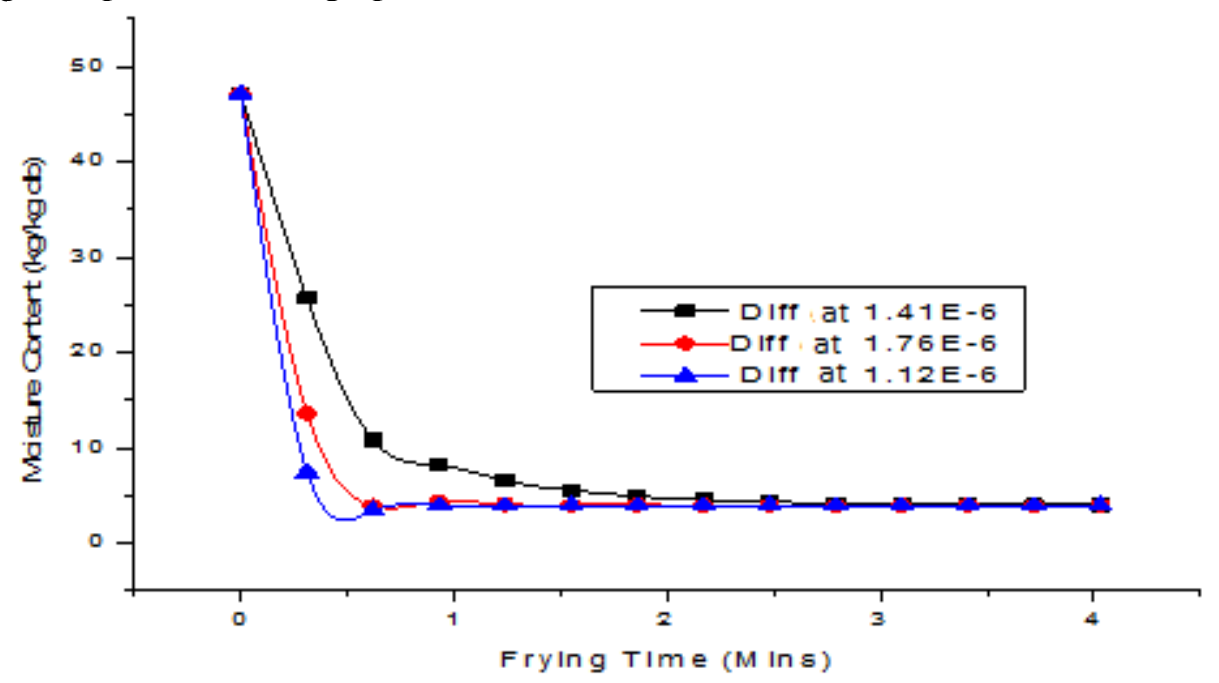

Figure 5. The effect of diffusivity parameter on the surface moisture content of plantain chips during frying process (temperature $=190^{\circ} \mathrm{C}$; initial moisture content $=63.17 \% \mathrm{db}$; chip thickness $=2 \mathrm{~mm}$ ) 


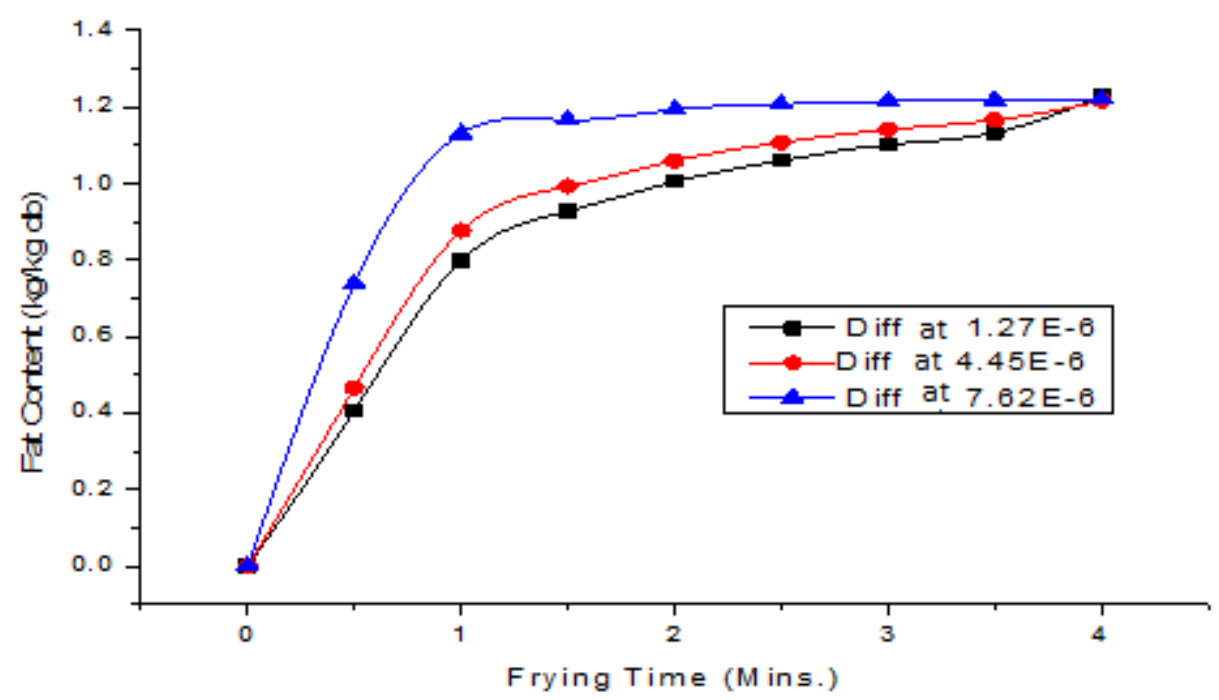

Figure 6. The effect of diffusivity parameter during the process of frying on the surface of the fat content of the plantain chips (frying temperature $=190^{\circ} \mathrm{C}$; chip thickness $=2 \mathrm{~mm}$ )

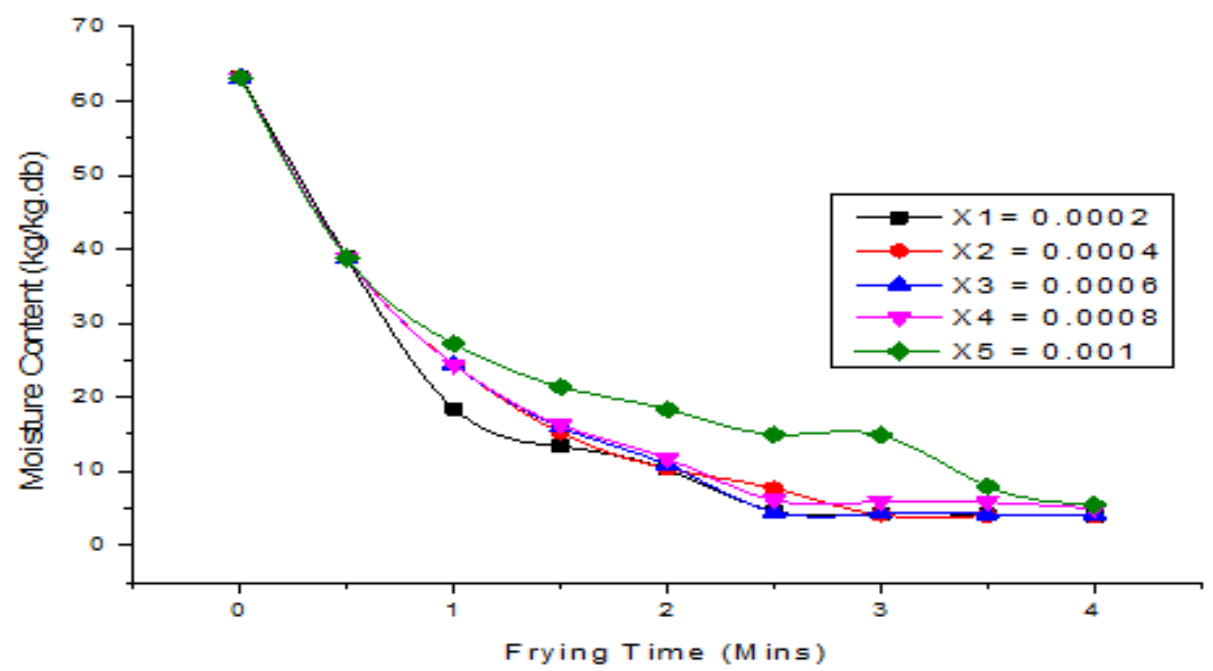

Figure 7. Moisture content distribution simulation during frying process (frying temperature $=190^{\circ} \mathrm{C}$; chip thickness $=2 \mathrm{~mm}$ )

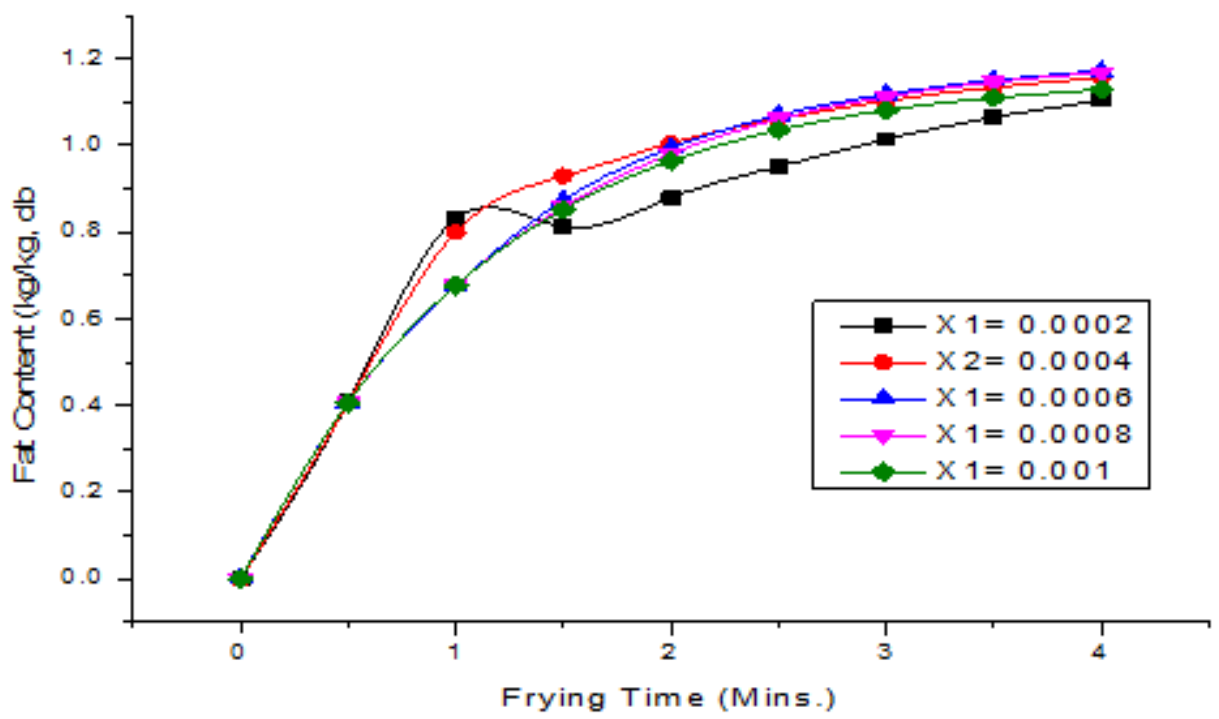

Figure 8. Fat content distribution simulation during frying process (frying temperature $=190^{\circ} \mathrm{C}$; chip thickness $=2 \mathrm{~mm}$ ) 


\section{CONCLUSION}

A numerical solution of the partial differential model that governs moisture and oil transfer in DFF process of ipekere was established. A comparison was made between the predicted and experimental results of moisture and oil transfer rate during the DFF towards the determination of the degree of the predictability. The simulated results predicted satisfactorily with less than $10 \%$ of mean relative deviation modulus of oil uptake and moisture loss at distinct operating conditions. The ranges of correlation coefficients values between predicted and experimental values for models of moisture and oil were $0.96-0.99$ and $0.94-0.99$, respectively. Thus, the developed mass transfer model can be used to predict oil uptake and moisture loss in DFF of ipekere. The predictions are vital for the design, scale-up and optimization of the DFF process conditions.

\section{REFERENCES}

1. Adedeji, A. A. and Ngadi, M. (2018). Impact of freezing method, frying and storage on fat absorption kinetics and structural changes of parfried potato. Journal of Food Engineering, 218: 2432. DOI: 10.1016/j.jfoodeng.2017.08.024.

2. Adedeji, A. A. and Ngadi, M. (2011). Porosity determination of deep-fat-fried coatings using pycnometer (Fried batter porosity determination by pycnometer). International Journal of Food Science and Technology, 46: 1266-1275. DOI: 10.1111/j.1365-2621.2011.02631.x.

3. Adedeji, A. A., Ngadi, M. O. and Raghavan, G. S. V. (2009). Kinetics of mass transfer in microwave precooked and deep-fat fried chicken nuggets. Journal of Food Engineering, 91: 146-153. DOI: 10.1016/j.jfoodeng.2008.08.018.

4. Adeyanju, J. A., Olajide, J. O. and Adedeji, A. A. (2016). Development of optimum operating conditions for quality attributes in deep-fat frying of dodo produced from plantain using response surface methodology. Food and Nutrition Sciences, 7: 1423-1433. DOI: 10.4236/fns.2016.714129.

5. AOAC. (2000). Official methods of analysis (17th ed). Association of Official Analytical Chemists. Washington DC.

6. Ateba, P. and Mittal, G. S. (1994). Modelling the deep-fat frying of beef meatballs. International Journal of Food Science and Technology, 29: 429-440. DOI: 10.1111/j.1365-2621.1994.tb02084.x.

7. Aurore, G., Berthe, P. and Louis F. (2009). Bananas, raw materials for making processed food products: A Review. Trends in Food Science and Technology, 20(2): 78-91. DOI: 10.1016/j.tifs.2008.10.003.

8. Azoubel, P. M. and Murr, F. E. X. (2002). Effect of sugar syrup concentration and temperature on the rate of osmotic dehydration of Apple. Journal of Food Science and Technology, 27(5):205-201. DOI: 10.1111/j.1365-2621.2008.01783.x.

9. Bouchin, P., Aguilera, J. and Pyle, D. (2003). Structure oil absorption relationships during deep-fat frying. Journal of Food Science, 68: 2711-2716. DOI: 10.1111/j.13652621.2003.tb05793.x

10. Bravo, J., Sanjuan, N., Ruales, J. and Mulet, A. (2009). Modelling the dehydration of apple slices by deep fat frying. Drying Technology, 27: 782-786. DOI: 10.1080/07373930902828187.

11. Chen, Y., and Moreira, R. G. (1997). Modelling of a batch deep-fat frying process for Tortilla chips. Food and Bioproducts Processing, 75(3):181-190. DOI: 10.1205/096030897531531.

12. Demirel, D. and Turhan, M. (2003). Air drying behaviour of Dwarf Cavendish and Gros Michel plantain slices. Journal of Food Engineering, 59(1): 1-11. DOI: 10.1016/S0260-8774(02)-00423-5.

13. Dobarganes, M. C, Velasco, J. and Dieffenbache, A. (2000). Determination of polar compounds polymerized and oxidized triacylglycerols, and diacylglycerols in oils and fats. Pure and Applied Chemistry, 72(8): 1563-1575. DOI: 10.1351/pac200072081563.

14. FAO (2013). Statistical Yearbook, Statistics Division, Food and Agriculture Organisation, Rome, Italy.

15. Farkas, B. E., Singh, R. P. and Rumsey, T. R. (1996). Modelling heat and mass transfer in immersion frying: model development. Journal of Food Engineering, 29(2): 211-226. DOI: 10.1016/0260-8774(95)00072-0.

16. Gamble, M. H., Rice, P. and Selman, J. D. (1987). Relationship between oil uptake and moisture loss during frying of potato slices. International Journal of Food Science and Technology, 22(3): 23322341. DOI: 10.1111/j.1365-2621.1987.tb00483.x. 
17. Garcia, M. A., Ferrero, C., Bertola, N., Martino, M. and Zaritzky, N. (2002). Edible coatings from cellulose derivatives to reduce oil uptake in fried products. Innovative Food Science and Emerging Technologies, 3(4): 391-397. DOI: 10.1016/S1466-8564(02)00050-4.

18. Innawong, B. (2001). Improving fried product and frying oil quality using nitrogen gas in a pressure frying system. (Ph.D). Virginia Polytechnic Institute and State University, Blacksburg, Virginia.

19. Kanazawa, K. and Sakakibara, H. (2000). High content of dopamine, a strong antioxidant, in Cavendish plantain. Journal of Agricultural and Food Chemistry, 48(3): 844-848. DOI: 10.1021/jf9909860.

20. Kassama, L. and Ngadi, M. (2005). Pore development and moisture transfer in chicken meat during deep-fat frying. Journal of Drying Technology, 23(4): 907-923. DOI: 10.1081/DRT-200054239.

21. Krokida, M. K., Oreopoulou, V., Maroulis, Z. B. and Marinos-Kouris, D. (2001). Effect of osmotic dehydration pretreatment on quality of French fries. Journal of Food Engineering, 49(4): 339-345. DOI: 10.1016/S0260-8774(00)00232-6.

22. Manjunatha, S. S., Ravi, N., Negi, P. S., Raju, P. S. and Bawa, A. S. (2012). Kinetics of moisture loss and oil uptake during deep fat frying of Gethi (Dioscorea kamoonensis Kunth) strips. Journal of Food Science and Technology. DOI: 10.1007/s13197-012-0841-6.

23. Marquez, G. and Anon, M. (1986). Influence of reducing sugars and amino acid in the colour development of fried potatoes. Journal of Food Science, 51(1): 157-160. DOI: 10.1111/j.13652621.1986.tb10859.x.

24. Mellema, M. (2003). Mechanism and reduction of fat uptake in deep-fat fried foods. Trends in Food Science and Technology, 14(9): 364-373.DOI: 10.1016/S0924-2244(03)00050-5.

25. Mohapatra, D., Mishra, S. and Sutar, N. (2010). Plantain and its byproduct utilization: An overview. Journal of Scientific and Industrial Research, 69, 323-329.

26. Moreira, R. G, Sun, X. and Chen, Y. (1997). Factors affecting oil uptake in tortilla chips in deep-fat frying. Journal of Food Engineering, 31(4), 485-98. DOI: 10.1016/S0260-8774(96)00088-x.

27. Ngadi, M. O., Watts, K. C. and Correia, L. R. (1997). Finite element modelling of heat and mass transfer during deep-fat frying of chicken drums. Journal of Food Engineering, 32(1): 11-20. DOI: 10.1016/S0260-8774(97)00095-2.

28. Pedreschi, F. (2012). Frying of potatoes: Physical, chemical and microstructural changes. Drying Technology, 30(7): 707-725. DOI: 10.1080/07373937.2012.663845.

29. Vitrac, O., Dufour, D., Trystram, G. and Raoult-Wack, A. (2002). Characterization of heat and mass transfer during deep-fat frying and its effect on cassava chip quality. Journal of Food Engineering, 53(2): 161-176. DOI: 10.1016/S0260-8774(01)00153-4.

30. Yamsaengsung, R. and Moreira, R. G. (2002). Modelling the transport phenomena and structural changes during deep fat frying, Part I: model development. Journal of Food Engineering, 53(1): 110. DOI: $10.1016 / \mathrm{S} 0260-8774(01) 00134-0$.

31. Ziaiifar, A. M., Achir, N., Courtois, F., Trezzani, I. and Trystram, G. (2008). Review on mechanisms, conditions, and factors involved in the oil uptake phenomenon during deep-fat frying process. International Journal of Food Science and Technology, 43(8): 1410-23. DOI: 10.1111/j.1365-2621.2007.01664.x.

32. Zhan, T., Li, J., Ding, Z. and Fan, L. (2015). Effects of initial moisture content on the oil absorption behaviour of potato chips during frying process, Food and Bioprocess Technology, 9(2): DOI: 10.1007/s11947-015-1625-6. 